\title{
Congenital malaria: Is it really rare?
}

\author{
Mandliya JC' $\mathbf{J C}^{1}$ Gupta $\mathbf{R}^{2}$ \\ ${ }^{1}$ Dr Jagdish Chandra Mandliya, Associate Professor, ${ }^{2}$ Dr Rajesh Gupta, Assistant Professor; both from the Department of \\ Pediatrics, Ruxmaniben Deepchand Gardi Medical College, Ujjain, M.P., India
}

Address for correspondence: Dr Jagdish Chandra Mandliya. Email: drjagdish1@yahool.co.in

\begin{abstract}
Congenital malaria is acquired from the mother prenatally or perinatally. In African countries congenital malaria is mainly caused by Plasmodium falciparum while in Asia and Europe, P.vivax is common. Postulated mechanism for congenital transmission of malaria parasites include maternal transfusion into the foetal circulation either at the time of delivery or during pregnancy, direct penetration through the chorionic villi or penetration through premature separation of placenta. Signs and symptoms include fever, restlessness, pallor, jaundice, poor feeding, vomiting, diarrhoea, cyanosis, hepatosplenomegaly and convulsions mostly between 10 and 30 days of age. Examination of peripheral blood by thick smear using light microscopy (LM) is the gold standard. Treatment of the congenital vivax malaria requires a blood schizonticide, like chloroquine. However, additional efforts should be made to establish safety profile, the correct dosage and formulation of Artemisinin-based combination therapy (ACT) in infants with a body weight of less than $5 \mathrm{~kg}$.
\end{abstract}

Keywords: Congenital malaria, Plasmodium falciparum, Pregnancy, Hepatosplenomegaly

\section{Background}

Malaria in infants is classified according to the time of infection. Congenital malaria, defined as asexual parasites detected in the cord blood or in the peripheral blood during the first week of life ${ }^{1}$, while neonatal malaria, which can occur within the first 28 days of life, is due to an infective mosquito bite after birth. $^{2}$ In many malaria-endemic countries, infants and children frequently die at home ${ }^{3}$ and the cause of death remains undetermined and unrecorded ${ }^{5,6,4}$.In endemic areas, distinguishing malaria acquired congenitally from that acquired by transmission from mosquitoes is difficult. ${ }^{7}$ Congenital malaria can be acquired by transmission of parasites from mother to child during pregnancy or perinatally during labour. ${ }^{8}$

Manuscript received: $10^{\text {th }}$ Aug 2013

Reviewed: $26^{\text {th }}$ Aug 2013

Author Corrected: $19^{\text {th }}$ Sep 2013

Accepted for Publication: $10^{\text {th }}$ Oct 2013
Pregnant women are more susceptible to malaria than nonpregnant women, especially in first and second pregnancy ${ }^{9}$. In the past, congenital malaria was thought to be extremely rare both in endemic and non - endemic areas ${ }^{10}$ but more recent studies however suggest that incidence has increased. ${ }^{11}$ In African countries congenital malaria is mainly caused by Plasmodium falciparum ${ }^{12}$ which is an important cause of abortions, miscarriages, premature births, intrauterine growth retardation and neonatal deaths, ${ }^{13}$ while in Asia P.vivax is common ${ }^{32}$. In European countries most cases are due to P.malariae and P. Vivax ${ }^{14}$.

\section{Problem areas}

Congenital malaria was first described in $1876 .{ }^{15}$ It is acquired from the mother prenatally or perinatally and is a serious problem in tropical areas ${ }^{13}$. 
Prevalence rate of congenital malaria between $0.3 \%$ and $46.7 \%$ have been obtained from both endemic and nonendemic areas ${ }^{16-18}$. In most cases of congenital malaria ,the baby is likely to have been infected while in-utero. ${ }^{19}$ More than 2000 million people live in the areas where malaria transmission occurs and are therefore at risk of being infected. ${ }^{8}$ Although congenital malaria develops in 01 percent of immune and 10 percent of nonimmune mothers in endemic areas , placental infection occurs in as many as one third of pregnant women. ${ }^{70}$ It follows that 1000 million people are exposed to the risk of malaria when pregnant. Globally between 75000 and 2,00,000 infant deaths are attributed to malaria infection in pregnancy every year..$^{20,21}$

The newborns of primigravidae are more susceptible to congenital malaria than those of the multigravidae. ${ }^{71}$ Congenital malaria cases are rarely reported in the USA. ${ }^{13}$ For the 81 cases of the congenital malaria reported in the USA in the past 40 years, the predominant infecting species was Plasmodium vivax. ${ }^{23}$

Most studies come from Sub-Saharan Africa, where approximately 25 million pregnant women are at risk of P.falciparum infection every year and one in four woman have evidence of placental infection at the time of delivery. P.falciparum infection during pregnancy in Africa rarely result in fever and therefore remain undetected and untreated. ${ }^{24}$

Compared to P.falciparum, P.vivax has a much wider distribution outside Africa and it extends far into the temperate zones. ${ }^{22}$ P.vivax is common in Asia, America ${ }^{24}$, Europe ${ }^{25}$, Singapore ${ }^{26}$ and Thailand ${ }^{27}$. In 2012, first case from Latin Amarica has been reported in which findings show that maternal P.vivax infection still occurs in areas in the pathway towards malaria eliminalation. ${ }^{28}$

\section{Causative agents}

Congenital malaria usually occurs in the offspring of a non- immune mother with P.vivax and P.malariae infection, although it can be observed with any of the human malaria species. ${ }^{13}$
A well documented risk factor for developing neonatal and congenital malaria is maternal $3^{\text {rd }}$ trimester malaria infection. ${ }^{29}$ The higher prevalence of congenital malaria due to $\mathrm{P}$. vivax than to $\mathrm{P}$. falciparum in non-endemic countries is well established. ${ }^{30,36}$ The most likely explanation is represented by the longer incubation time and the relatively wider clinical presentation in P.vivax malaria which allows for more maternal episodes to go undiagnosed and untreated . A potential additional determinant is represented by the contraindication during pregnancy of drugs that can eradicate the liver stage of parasite thus increasing the likelihood of late relapse. ${ }^{25}$ P.falciparum has been documented in 6 out of 7 case studies of congenital malaria reported from Sri Lanka.$^{31}$

\section{Mechanism of transmission}

Postulated mechanism for congenital transmission of malaria parasites include maternal transfusion into the foetal circulation either at the time of delivery or during pregnancy, direct penetration through the chorionic villi or penetration through premature separation of placenta. ${ }^{31}$ The remarkable capacity of the foetus to resist infection has been demonstrated. ${ }^{32}$

This resistance can reflect the physical barrier of the placenta to infected red cells, the passive transfer of maternal IgG antibodies and the unfavourable environment offered by foetal erythrocytes for plasmodial replication due to their foetal haemoglobin composition and low free oxygen tension. ${ }^{31,33}$

In pregnancy, reduced lymphoproliferative response sustained by elevated levels of serum cortisol, loss of cellmediated immunity in the mother, the presence of placenta, a new organ in the primigravidae, allows the parasite to bypass the existing host immunity, or allows placentaspecific phenotypes of $P$. falciparum to multiply. Pregnant women display a bias towards type- 2 cytokines

and are therefore susceptible to diseases requiring type-1 responses for protection like TB, malaria. P. falciparum has the unique ability of cytoadhesion. 
Chondroitin sulfate A and hyaluronic acid are the adhesion molecules for parasite attachment to placental cells. ${ }^{34}$

\section{How it presents?}

The first sign or symptom most commonly occurs between 10 and 30 days of age (range 14 hours to several months of age). ${ }^{13}$ Signs and symptoms include fever, restlessness, pallor, jaundice, poor feeding, vomiting, diarroea, cyanosis, hepatosplenomegaly ${ }^{13}$ and convulsions ${ }^{35}$.

Severe thrombocytopenia with ${ }^{15}$ or without bleeding is also a frequently reported feature of congenital malaria. ${ }^{36,37,38}$ Infants with congenital or neonatal malaria may have a different clinical presentation than older children, and diagnosis may be confused with other neonatal diseases due to an overlap of clinical manifestation. ${ }^{39}$

Because of its non specific presentation with fever during the first 3 months of life, it is an important differential diagnosis when evaluating such infants with fever in the pediatric emergency department. ${ }^{40}$ Some studies show atypical presentation of congenital malaria with no fever. ${ }^{41}$

In an article published in Archives of Pediatrics (2000), Balaka B. et.al. differentiated congenital malaria disease (CMD) from congenital malaria infection (CMI) in an endemic area. ${ }^{42}$ (Table 1$)$

Table 1: Clinical differentiation of Congenital Malaria

\begin{tabular}{|l|l|}
\hline Congenital Malaria disease (CMD) & clinical manifestations associated with positive thick and thin \\
& blood films in a mother and her newborn \\
\hline Congenital Malaria infection (CMI) & positive parasitemia but no clinical manifestations \\
\hline
\end{tabular}

An association between obstructive jaundice and neonatal malaria was noted by Patwari. ${ }^{43}$ Hepatomegaly is rather less commonly noted than splenomegaly. ${ }^{44}$ Younger the age of malarial onset, greater the severity of hepatic damage (and therefore jaundice). ${ }^{45}$

In a case study by Hewson MP, illustrates the difficulty of early diagnosis and the atypical nature of presentation in a preterm infant. ${ }^{46}$

Analysing the morbidity due to the congenital malaria in early infancy, Poespoprodjo JR et.al. noted that the case fatality rate was similar for inpatients with P.falciparum malaria and P. vivax whereas severe malarial anaemia was more prevalent among those with P.vivax malaria. ${ }^{47}$

\section{How to diagnose?}

Differentiating between congenital and acquired neonatal malaria can be difficult, especially in areas of intense malaria transmission. ${ }^{66}$ In areas with limited resources, the capacity to diagnose malaria in young infants may be limited ${ }^{67,68}$ and any issues with quality or accuracy of the diagnostic technique may result in the diagnosis of malaria being missed. ${ }^{6}$ For many years, the diagnosis of plasmodium infection has been based on the examination of peripheral blood by thick smear using light microscopy (LM). This is a very specific test that performs when parasitemias are $>1000$ parasites $/ \mathrm{L} .{ }^{48-50}$ Other technique used in the diagnosis of malarial infection include rapid diagnostic test (RDTs). ${ }^{51}$

Nucleic acid based amplification tests such as nested polymerase chain reaction (nPCR) have been widely used in major laboratories. ${ }^{52}$ Both microscopy and PCR allow species discrimination, but both also identifies different parasite stages. ${ }^{53}$

Histopathology (HP) is also suitable for diagnosis of plasmodial infection in placental tissue. This is the gold standard in such cases.${ }^{54}$ Histopathology can detect parasites, malarial pigment (hemozoin) or both, any of which can establish the diagnosis. ${ }^{55,56}$ (Table 2) 
Table 2: Histopathological classification of Placental tissue inflammation due to Malaria parasite

\begin{tabular}{|l|l|}
\hline Acute active infection & presence of parasites with pigment scarce or absent \\
\hline Chronic active infection & presence of parasites and pigments relatively abundant \\
\hline Past infections & exclusive presence of pigments \\
\hline
\end{tabular}

Out of above mentioned investigative modalities, LM has the best operational - economical qualification. nPCR and HP perform better compared with LM but field implementation of these two techniques remain a problem..$^{51}$

Efforts are being made to design nucleic based test suitable for field amplification in rural settings, including isothermal loop amplification (LAMP). ${ }^{57-60}$ The LAMP reactions are easy to set up and results can readily be assessed by detection of turbidity or more importantly, simply through the naked eye. ${ }^{61}$

\section{How to treat?}

Treatment of the congenital vivax malaria requires a blood schizonticide, like chloroqine. ${ }^{25}$ Due to the absence of an exoerythrocytic life cycle in congenitally acquired malaria, chloroquine is the drug of choice for treatment. Unnecessary administration of primaquine phosphate for P.vivax infections was found in a review of cases from 1966 to 2005 in the United States. ${ }^{23}$ Infection with chloroquine resistant strain require multiple drug therapy. ${ }^{62}$ There are no official data on how to use ACT in this age group, despite the fact that malaria can occur at a very young age and that ACT offers greater efficacy and tolerability compared with quinine. At this time, a clear recommendation on the use of ACT can be difficult, due to a lack of data in infants with a body weight of less than 5 $\mathrm{kg} \cdot{ }^{39}$

\section{Prevention strategy}

Pregnant women in malaria endemic region may experience a variety of adverse consequences from malaria infection including maternal anemia, placental accumulation of parasites, low birth weight (LBW) from prematurity and IUGR, foetal parasite exposure , congenital infections and infant mortality linked to preterm LBW and IUGR- LBW. ${ }^{20}$

Preventive strategies include regular chemoprophylaxis, intermittent preventive treatment (IPT) with antimalarials and insecticide treated bednets. ${ }^{63}$ Intermittent preventive treatment in pregnancy at antenatal visits with two doses of Sulfadoxime - Pyrimethamine (SP) is recommended for population groups in areas of high transmission who are particularly vulnerable to Plasmodium infection and its consequences. ${ }^{64}$

The WHO $20^{\text {th }}$ malarial committee designated IPT as the preferred approach to reduce the adverse consequences of malaria during pregnancy. ${ }^{65}$

\section{Conclusion}

Congenital malaria was supposed to be rare in the past but recent data suggests its higher prevalence in endemic regions of the world especially in Africa and Asia. High suspicion of index should be considered diagnosing malaria in pregnancy to prevent congenital malaria. Apart from conventional preventive measures, it is recommended to develop evidence based diagnostic criteria and treatment guidelines for congenital malaria.

Funding: Nil

Conflict of interest: Nil

Permission from IRB: Yes

\section{References}

1. Falade C, Mokuolu O, Okafor H, Orogade A, Falade A, Adedoyin O, Oguonu T, Aisha M, Hamer DH, Callahan MV. Epidemiology of congenital malaria in Nigeria: a multi-centre study. Trop Med Int Health. 2007;12:12791287. 
2. Mukhtar M. The growing incidence of neonatal malariaa situational review in developing countries. Niger J Med. 2007; 16:25-30.

3. Lawn JE, Cousens S, Zupan J. 4 million neonatal deaths: when? Where? Why? Lancet. 2005;365:891-900.

4. Sacarlal J, Nhacolo AQ, Sigauque B, Nhalungo DA, Abacassamo F, Sacoor CN, Aide P, Machevo S, Nhampossa T, Macete EV, Bassat Q, David C, Bardají A, Letang E, Saúte F, Aponte JJ, Thompson R, Alonso PL. A 10 year study of the cause of death in children under 15 years in Manhica. Mozambique. BMC Publ Health. 2009;9:67.

5. Bardaji A, Sigauque B, Sanz S, Maixenchs M, Ordi J, Aponte JJ, Mabunda S, Alonso PL, Menéndez C. Impact of malaria at the end of pregnancy on infant mortality and morbidity. J Infect Dis. 2011;203:691-699.

6. Abdullah S, Adazu K, Masanja H, Diallo D, Hodgson A, Ilboudo-Sanogo E, Nhacolo A, Owusu-Agyei S, Thompson R, Smith T, Binka FN. Patterns of age-specific mortality in children in endemic areas of sub-Saharan Africa. AmJTrop Med Hyg. 2007;77:99-105.

7. Feigin,Cherry,Demmler,Kaplan. Congenital malaria .Text book of Pediatric Infectious Diseases. $5^{\text {th }}$ ed;2:2718.

8. Menendez C. Malaria during pregnancy: A priority area of malaria research and control. Parasitol Today. 1995;11:178-183.

9. Rogerson SJ, Hvjjd L, Duffy PE, Leke RFG, Taylor D. Malaria in pregnancy: pathogenesis and immunity. Lancet. 2007;7:105-116.

10. Sierez JY, De Pontual L, Poilane I, Ledeur F, Haouchine D, Hassine Lac. Congenital malaria as result of Plasmodium malariae in an infant born to a HIVseropositive woman. Trop Med. 2005;65:477-81.

11. Fischer PR. Malaria and Newborn. J Trop Pediatr. 2003;49:132-134.
12. Ibhanesebhor SE. Clinical characteristics of neonatal. J Trop Pediatr. 2005;65:477-81.

13. Kliegman RM,Behrman RE,Jenson HB, Stanton BF. Congenital malaria. Nelson textbook of Pediatrics.2008;18:1479

14. Hyacinth I. Hyacinth, Stephen O, Christopher S. Yilgwan. Summary Description of 24 Cases of Neonatal Malaria Seen at a Tertiary Health Center in Nigeria. Iran J Pediatr. 2012; 22(1): 87-91.

15. Romand S, Bouree P, Gelez J, Bader-Meunier B, Bisaro F, Dommergues JP. Congenital malaria. Infected twins born to an asymptomatic mother. Presse Medicale. 1994;23(17):797-800.

16. Fischer PR. Malaria and new born. J Trop Pediatr. 2003;49:132-134.

17. Bassey AE, Ejezie GC, Alaribe AA, Useh MF, Udo JJ, Ekanem AD. Congenital malaria in Calabar, Cross River State, Nigeria. Mary Slessor J Med. 2005;5:37-40.

18. Obiajunwa PO, Owo JA, Adodu OO. Prevalence of congenital malaria in Ile-Ife, Nigeria. J Trop Pediatr. 2005;51:219-222.

19. Remington JS, Klainm JO. Infectious Diseases of the Fetus and Newborn Infant. 3rd ed. Philadelphia, PA: Saunders; 1995. pp. 765-768.

20. Steketee RW, Nahlen BL, Parise MC, Menendez C. The burden of malaria in pregnancy in malaria endemic areas. Am J Trop Med Hyg. 2001;64:28-35.

21. World Health Organization The African Malaria Report 2003. 2003.

http://www.rbm.who.int/amd2003/amr/toc.htm

22. Price RN, Tjitra E, Guerra CA, Yeung S, White NJ, Anstey NM. Vivax malaria: neglected and not benign. Am J Trop Med Hyg. 2007;77:79-87. 
23. Lesko CR, Arguin PM, Newman RD. Congenital malaria in the United States: a review of cases from 1966 to 2005. Arch Pediatr Adolesc Med. 2007;161(11):1062-7.

24. Desai M, Kuile FO, Nosten F, McGready R, Asamoa K, Brabin B, Newman RD. Epidemiology and burden of malaria in pregnancy. The Lancet Infectious diseases.2007;7(2):93-104

25. Veronica DP, Maurizio G, Alberto M, Vania S, Antonio

R, Francesco C. Congenital Plasmodium vivax malaria mimicking neonatal sepsis: a case report.Malar J. 2010; 9: 63.

26. Lee WW, Singh M, Tan CL. A recent case of congenital malaria in Singapore. Singapore Med J. 1996;37:541-543.

27. Wivanitkit V. Congenital malaria in Thailand, an appraisal of previous cases. Pediatrics Intnl. 2006;48:562565.

28. Castellanos ME, Bardají A, Menegon M, Mayor A, Desai M, Severini C, Menéndez C, Padilla N. Plasmodium vivax congenital malaria in an area of very low endemicity in Guatemala: implications for clinical and epidemiological surveillance in a malaria elimination context. Malar J. 2012 ;11(1):411.

29. Sotimehin SA, Runsewe-Abiodun TI, Oladapo OT, Njokanma OF, Olanrewaju DM. Possible risk factors for congenital malaria at a tertiary care hospital in Sagamu, Ogun state, southwest Nigeria. J Trop Pediatr. 2008;54(5):313-20.

30. Nosten F, McGready R, Simpson JA, Thwai KL, Balkan S, Cho Thei, Hkirijaroen L, Looareesuwan S, White NJ. Effects of Plasmodium vivax malaria in pregnancy. Lancet. 1999;354:546-549.

31. De Silva DHG, Mendis MN, Premratne UN, Jayatilleke S, Soyza PE. Congenital malaria due to Plasmodium vivax: a case report from Sri Lanka. Trans of the Royal Soc of Trop Med and Hyg. 1982;76(1):33-35
32. Miller IJ, Telford SR III. Placental malaria. N Eng J Med. 1996;335:98.

33. Wilson RJ, Pasvol G, Weatherall DJ. Invasion and growth of Plasmodium falciparum in different types of human erythrocyte. Bull World Health Organ. 1977;55:179-186.

34. Kakkilaya BS. Malaria and pregnancy. 2009, http://www.malariasite.com

35. Thapa BR, Narang A, Bhakoo ON. Neonatal malaria: A clinical study of congenital and transfusional malaria. $\mathrm{J}$ Trop Paediatr. 1987;33(5):266-68

36. Voittier G, Arsac M, Farnoux C, Mariani-Kurdjian P, Baud O, Aujard Y. Congenital malaria in neonates: two case report and review of literature. Paediatrica. 2008;97:500-512.

37. Lesko CR, Arguin PM, Newman RD. Congenital malaria in the United States. Arch Pediatr Adolesc Med. 2007;161:1062-1067.

38. Baspinar O, Bayraktaroglu Z, Karsligil T, Bayram A, Coscun Y. A rare case of anemia and thrombocytopenia in a newborn: congenital malaria. Turk Journ Pediatr. 2006;48:63-658.

39. D Alessandro U, Ubben D, Hamed K, Ceesay SJ, Okebe J, Taal M, Lama EK, Keita M, Koivogui L, Nahum A, Bojang K, Sonko AA, Lalya HF, Brabin B. Malaria in infants aged less than six months - is it an area of unmet medical need? Malar J. $2012 ; 11(1): 400$

40. Hagmann S, Khanna K, Niazi M, Purswani M, Robins EB. Congenital malaria, an important differential diagnosis to consider when evaluating febrile infants of immigrant mothers. Pediatr Emerg Care. 2007;23(5):326-9.

41. Valecha N, Bhatia S, Mehta S, Sukla B, Dash AP. Congenital malaria with atypical presentation: A case report from low transmission area in India.Malar J. 2007; 6: 43 . 
42. Balaka B, Agbere AD, Bonkoungou P, Kessie K, Assimadi K, Agbo K. Congenital malarial disease due to Plasmodium falciparum in high-infection-risk newborn.Arch Pediatr. 2000;7(3):243-8.

43. Patwari A. Aneja S, Berry AM. Ghosh S. Neonatal mailairiai-a clinico-haematological profile. Itidiati Pediatr 1978;15/10:847-9.

44. Yeager AS. In: Rcmington JS. Klcin JO, cds. Infecious diseases of the fetus and newborn $2^{\text {nd }}$ ed. Philaidelphia: W B Saunders. 1984;563-6.

45. M Davenport. Neonatal malaria and obstructive jaundice.Departmnent of Paediatric Surgery, Leeds General Infirmary.Archives of Disease in Childhood, $1986 ; 61: 516$

46. Hewson MP, Simmer K, Blackmore T. Congenital malaria in a preterm infant. J Paediatr Child Health. 2003;39(9):713-5.

47. Poespoprodjo JR, Fobia W, Kenangalem E, Lampah DA, Hasanuddin A, Warikar N, Sugiarto P, Tjitra E, Anstey NM, Price RN. Vivax malaria: a major cause of morbidity in early infancy. Clin Infect Dis. 2009 ;48(12):1704-12.

48. López-Antuñano F. In: Diagnóstico de malaria. LópezAntuñano FJ, Schmunis G, editors. Washington DC: WHO-PAHO; 1988. pp. 39-50.

49. Makler M, Palmer C, Ager A. A review of practical techniques for the diagnosis of malaria. Ann Trop Med Parasitol. 1998;92:419-433.

50. PAHO Pan American Health Organization. Malaria in the Americas. PAHO Bull. 1996;17:1-18.

51. Ivón M. C, Mary L. U, Carolina C, Alexander FG, Jaime CF, and Amanda M. Diagnosis of Gestational, Congenital, and Placental Malaria in Colombia: Comparison of the Efficacy of Microscopy, Nested Polymerase Chain Reaction, and Histopathology. Am J Trop Med Hyg. 2011; 84(6): 929-935
52. Snounou G, Viriyakosol S, Zhu X, Jarra W, Pinheiro L, Do Rosario V, Thaithong S, Brown K. High sensitivity of detection of human malaria parasites by the use of nested polymerase chain reaction. Mol Biochem Parasitol. 1993;61:315-320.

53. Hanscheid T. Diagnosis of malaria: a review of alternatives to conventional microscopy. Clin Lab Haematol. 1999;21:235-245.

54. Rogerson S, Mkundika P, Kanjala M. Diagnosis of Plasmodium falciparum malaria at delivery: comparison of blood film preparation methods and of blood films with histology. J Clin Microbiol. 2003;41:1370-1374.

55. Bulmer J, Rasheed F, Francis N, Morrison L, Greenwoods B. Placental malaria. I. Pathological classification. Histopathology. 1993;22:211-218.

56. Bulmer J, Rasheed F, Morrison L, Francis N, Greenwood B. Placental malaria. II. A semi-quantitative investigation of the pathological features. Histopathology. 1993;22:219-225.

57. Lucchi N, Demas A, Narayanan J, Sumari D, Kabanywanyi A, Kachur S, Barnwell J, Udhayakumar V. Real-time fluorescence loop mediated isothermal amplification for the diagnosis of malaria. PLoS One. 2010;5:e13733.

58. Han E, Watanabe R, Sattabongkot J, Khuntirat B, Sirichaisinthop J, Iriko $\mathrm{H}$, Jin $\mathrm{L}$, Takeo $\mathrm{S}$, Tsuboi $\mathrm{T}$. Detection of four Plasmodium species by genus- and species-specific Loop-Mediated Isothermal Amplification for clinical diagnosis. J Clin Microbiol. 2007;45:25212528 .

59. Paris D, Imwong M, Faiz A, Hasan M, Yunus E, Silamut K, Lee S, Day N, Dondorp A. Loop-mediated isothermal PCR (LAMP) for the diagnosis of falciparum malaria. Am J Trop Med Hyg. 2007;77:972-976.

60. Poon L, Wong B, Ma E, Chan Q, Chow L, Abeyewickreme W, Tangpukdee N, Yuen K, Guan Y, Looareesuwan S, Peiris J. Sensitive and inexpensive 
molecular test for falciparum malaria: detecting Plasmodium falciparum DNA directly from heat-treated blood by loop-mediated isothermal amplification. Clin Chem. 2006;52:303-306.

61. Snounou G. Rapid, sensitive and cheap molecular diagnosis of malaria: is microscopy on the way out? Future Microbiol. 2007;2:477-480.

62. Hindi RD, Azimi PH. Congenital malaria due to Plasmodium falciparum. Pediatrics. 1980;66(6):977-9.

63. Shulman CE, Dorman EK. Importance and prevention of malaria in pregnancy.Trans R Soc Trop Med Hyg. 2003;97(1):30-5.

64. World Malaria Report (WHO). 2011;35

65. GHS/NMCP/Global Fund/JHPIEGO, author. Intermittent Preventive Treatment (IPT) of malaria in pregnancy. 2005 May;29-31

66. Fischer PR, Nyirjesy P, Toko RM. Congenital malaria in twins. West J Med. 1995;163:395-396.
67. Hailegiorgis B, Girma S, Melaku Z, Teshi T, Demeke L, Gebresellasie S, Yadeta D, Tibesso G, Whitehurst N, Yamo E, Carter J, Reithinger R. Laboratory malaria diagnostic capacity in health facilities in five administrative zones of oromia regional state. Ethiopia. Trop Med Int Health. 2010;15:1449-1457.

68. Ishengoma DR, Derua YA, Rwegoshora RT, Tenu F, Massaga JJ, Mboera LE, Magesa SM. The performance of health laboratories and the quality of malaria diagnosis in six districts of Tanzania. Ann Trop Med Parasitol. 2010;104:123-135.

69. Uneke CJ. Congenital Plasmodium falciparum malaria in sub-Saharan Africa: a rarity or frequent occurrence? Parasitol Res. 2007;101:835-842.

70. Joffe A, Jadavji T. Congenital malaria : A case report of a preventable disease.Pedatr.Infect.Dis.J. 1990; 9:522523.

71. Olabisi A., Ejezie GC, Friday A .Odey,Chioma M.Congenital malaria in Calabar,Nigeria:The molecular perspective.Am J Trop Med Hyg.2011;84(3):386-389

\section{How to cite this article?}

Mandliya JC, Gupta R. Congenital malaria: Is it really rare? Int J Med Res Rev 2013;1(4):195-202. doi:10.17511/ijmrr.2013.i04.12 